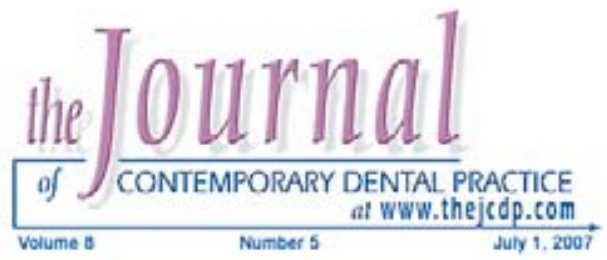

\title{
Surface Roughness and Adherence of Candida Albicans on Soft Lining Materials as Influenced by Accelerated Aging
}
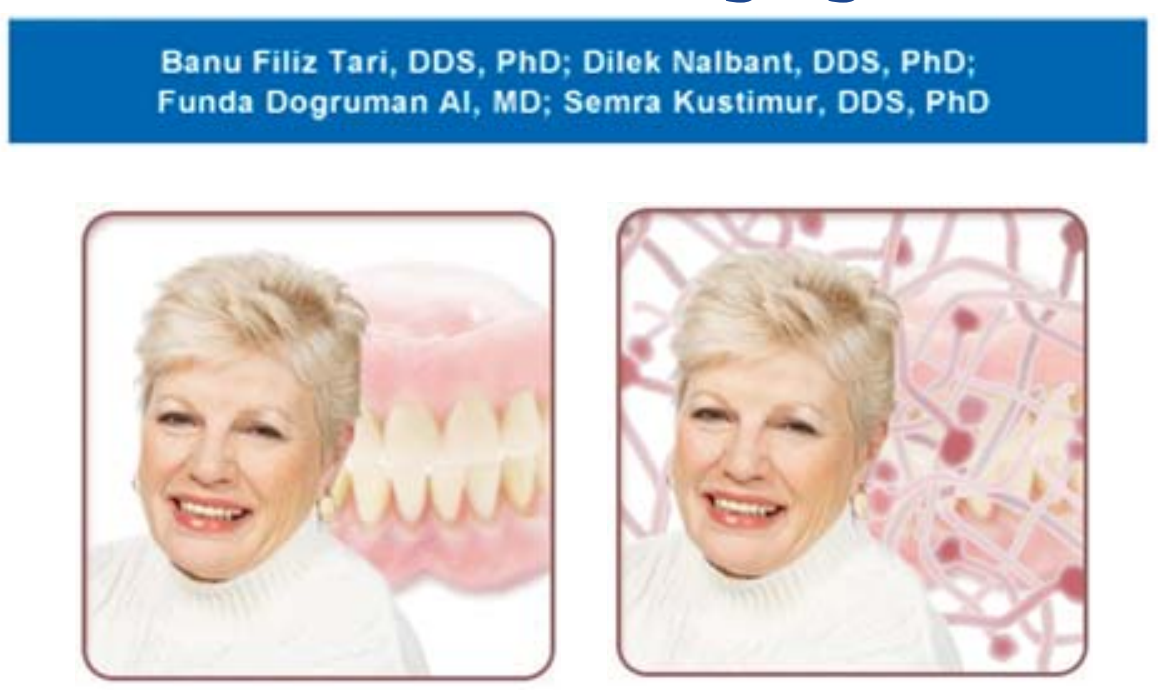

\begin{abstract}
Aim: Candida albicans (C. albicans) has been widely associated with the etiology of denture-related stomatitis and has been found on soft denture lining materials. The aim of this study was to examine the surface roughness and adherence of $C$. albicans to saliva coated and non-coated soft lining materials by subjecting them to an in vitro accelerated aging test.

Methods and Materials: Samples were prepared from three soft lining materials (Visco Gel, Ufi Gel P, Molloplast B). Surface roughness measurements and adhesion of $C$. albicans were examined before and after an aging process. The stimulated human whole saliva was used to assess its effect on adhesion.

Results: The aging process promotes the surface roughness of soft lining materials. The aging surface roughness of Visco Gel was significantly higher than Ufi Gel P and Molloplast B. No significant difference was observed between non-aged and uncoated materials, but aged and uncoated soft lining materials showed a greater adherence of $C$. albicans. No significant difference was observed between non-aged and saliva coated materials, but aged and saliva coated soft lining materials showed a greater adherence of $C$. albicans.

Conclusions: Candidosis induced by $C$. albicans is the most common fungal infection. Awareness of susceptibility of soft lining materials to the adherence of $C$. albicans is an important factor in their selection. The use of soft lining materials with smooth surfaces minimizes the adherence of $C$. albicans.
\end{abstract}

(c) Seer Publishing 
Keywords: Soft lining materials, C. albicans, surface roughness, adhesion, in vitro accelerated aging, saliva

Citation: Tari BF, Nalbant D, Dogruman Al F, Kustimur S. Surface Roughness and Adherence of Candida Albicans on Soft Lining Materials as Influenced by Accelerated Aging. J Contemp Dent Pract 2007 July;(8)5:018-025.

\section{Introduction}

It is well known candidosis induced by Candida albicans (C. albicans) is the most common fungal infection in human beings. ${ }^{1,2}$ The most prevalent form of oral candidosis is chronic atrophic candidosis (CAC) occurring as a candidal associated denture stomatitis characterized by erythema of the palate beneath the mucosal surface of the upper denture. ${ }^{3}$ The predisposing factors of infections caused by Candida species can be divided into systemic and local factors. Some of the systemic factors include age, endocrine diseases, systemic steroids and antibiotics, concurrent infections, and deficiency states. Local factors include salivation reduction, smoking, topical antibiotic or steroid treatment, coexistent oral mucosal disease, and especially the wearing of dentures. ${ }^{1,2}$ Prevalence has been reported at $11-67 \%$ in complete dentures. ${ }^{4,5}$

Soft denture liners may be defined as soft polymers which may be applied to the fitting or mucosal surface of a denture for the purpose of reducing and more evenly distributing the occlusal load on the underlying mucosal tissues. The use of soft denture liners has increased in recent years in an effort to achieve some measure of redistribution and reduction of locally damaging occlusal forces of dentures on the underlying oral tissues. ${ }^{6}$ These materials can be classified as provisional or definitive according to their composition of either silicone rubber or acrylic resin, and they can be either chemically or heat polymerized. ${ }^{7,8}$

The adherence of $C$. albicans to host cells or polymers such as denture acrylic resin and soft lining materials is an essential initial step in the successful colonization and development of an infection. ${ }^{9,10,11}$ Soft lining materials have been found to be more prone to microbial adhesion than acrylic resin denture base materials. They

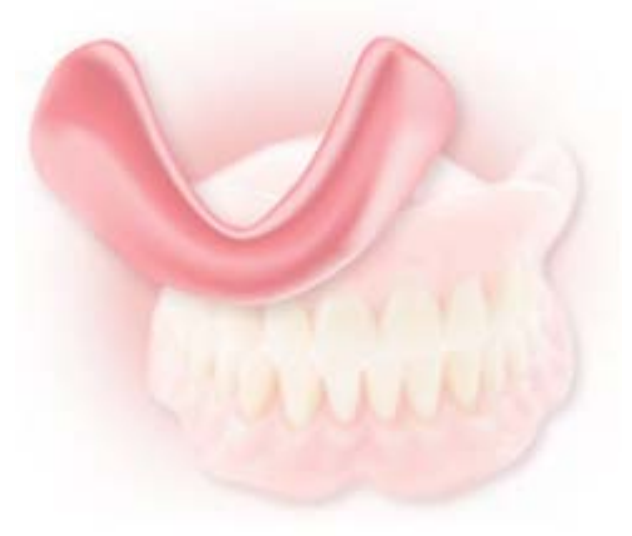

have demonstrated the ability to interact with oral microorganisms because of their surface texture and the physical and chemical affinity of the materials. ${ }^{12,13}$ Radford et al. ${ }^{4}$ reported $C$. albicans adhered in greater numbers to soft lining materials compared with acrylic surfaces. Verran and Maryan ${ }^{10}$ showed more fungal adhesion was found on rough surfaces than smooth surfaces and counted more cells on rough silicone than on rough acrylic surfaces.

Only limited data are available on the interactions between soft lining materials and $C$. albicans, however, its growth on these lining materials is thought to be an important factor. Although the lining materials are known to show changes in their physical properties with age, little attention has been paid to the growth of Candida when aging of the material has occurred. ${ }^{14}$ It is apparent the relationship between the salivary or serum pellicle on denture material surfaces and candidal colonization is a complex subject, particularly when the surface aging of soft lining materials are taken into account. ${ }^{15}$

When wearing a denture, the base becomes colonized with pellicles composed of salivary or serum proteins which may provide receptor 
Table 1. Soft denture lining materials used in the study.

\begin{tabular}{||l|l|l|}
\hline \multicolumn{1}{|c|}{ Material } & \multicolumn{1}{|c|}{ Type } & \multicolumn{1}{c|}{ Manufacturer } \\
\hline Visco Gel & Cold-cured acrylic resin soft lining material. & $\begin{array}{l}\text { Dentsply Ltd., De Trey } \\
\text { Division, Weybridge, U.K. }\end{array}$ \\
\hline Ufi Gel P & Cold-cured silicone soft lining material. & $\begin{array}{l}\text { Voco, Postfach 767, D-27457 } \\
\text { Cuxhafen, Germany }\end{array}$ \\
\hline Molloplast B & Heat-cured silicone soft lining material. & $\begin{array}{l}\text { Detax Karl Huber GmbH, } \\
\text { Ettlingen, Germany }\end{array}$ \\
\hline
\end{tabular}

sites for the adherence of microorganisms; surface roughness is a contributing factor in the colonizing process. ${ }^{8,16,17}$

Recent investigations have reported the continuous swallowing or aspiration of microorganisms from denture plaque exposes patients to the risks of unexpected infections. ${ }^{3,11,18}$ Because of the clinical importance of the growth and adhesion of $C$. albicans on the soft lining materials, the aim of the present study was to determine the surface roughness and $C$. albicans adhesion on saliva coated and non-coated soft lining materials by subjecting them to an in vitro accelerated aging test.

\section{Methods and Materials}

\section{Sample Preparation}

Three different soft lining materials: Visco Gel (Dentsply Ltd., De Trey, Division, Weybridge, UK), Ufi Gel P (Voco, Cuxhafen, Germany), and Molloplast B (Detax Karl Huber GmbH, Ettlingen, Germany) were used in this study. The compositions of the soft lining materials are shown in Table 1.

All samples were processed against glass slides with dimensions of $15 \mathrm{~mm} \times 1.5 \mathrm{~mm}$ using an aluminum mold. A clean technique was adopted to reduce contamination of the surface to be assessed for adhesion.

The cold cured soft lining materials (Visco Gel, Ufi Gel P) were processed according to the manufacturers' directions and made to a uniform size (15 mm diameter $X 1.5 \mathrm{~mm}$ thickness) using an aluminum mold and to a uniform surface roughness by allowing polymerization to occur against identical glass surfaces.
The heat cured soft lining material (Molloplast B) samples measuring $15 \mathrm{~mm}$ in diameter were cut from a $1.5 \mathrm{~mm}$ thickness of red boxing wax. Each wax sample was mounted onto the same glass surface and placed into the mold with glass slides. Samples were flasked with vacuum spatulated dental stone in the usual manner. All samples were processed according to the manufacturers' instructions. ${ }^{9,10}$

Fifty samples were made from each material. Ten of the 50 samples of each material were used for the measurement of surface roughness, and the remaining 40 samples were used for the adherence assay of $C$. albicans.

\section{Weathering Procedure}

After baseline measurements of surface roughness were made, each sample was mounted on a panel that attached to the frame of an accelerated weathering tester ${ }^{19}$ (Q-U-V, Q-Panel Company, Cleveland, OH, USA). Adhesion assays were repeated after a second set of samples were subjected to an accelerated aging chamber. ${ }^{20}$ The weathering cycle was programmed for each material according to their usage period in the mouth as preferred by manufacturers (Table 2). The samples were continuously exposed to a visible ultraviolet and visible light and sprayed with distilled water for 3.5 minutes at the beginning of every condensation cycle. The humidity in the chamber was maintained at $90^{\circ} \mathrm{C}$, the UV temperature at $60^{\circ} \mathrm{C}$, and the condensation temperature at $40^{\circ} \mathrm{C}$.

\section{Surface Roughness of Soft Lining Materials} Each sample of soft lining materials was boxed using boxing wax and poured using Type IV die stone (Tritech, Deltastone, Germany) to create gypsum samples for indirect measurements. 
Table 2. The usage period, aging time, and sample number of the materials used in the study.

\begin{tabular}{|l|l|l|l|}
\hline \multicolumn{1}{|c|}{ Material } & \multicolumn{1}{c|}{ Usage Period } & \multicolumn{1}{c|}{ Aging Time } & \multicolumn{1}{c|}{ Sample Number } \\
\hline Visco Gel & 3 weeks & 17 hours & 30 \\
\hline Ufi Gel P & 6 months & 138 hours & 30 \\
\hline Molloplast B & 2 years & 600 hours & 30 \\
\hline
\end{tabular}

The die stone was mixed according to the manufacturer's instructions with vacuum spatulation equipment (Whip Mix Corp., Louisville, KY, USA).

The surface roughness of the samples was measured with a Surtronic 10 profilometer (Taylor Habson Ltd. Leicester, England) where a stylus traverses across the layer of the surface and an amplified trace of the profile is provided. ${ }^{21}$ The surface roughness value $(\mathrm{Ra})$ is the arithmetical average of all departures of the profile through the mean sample length.

Direct surface roughness measurements were not obtained from the soft lining material samples because they were too thin and easily distorted. As a result, indirect measurements on stone models were used. Like impression materials, soft lining materials provide a mirror image of the surface against which it is processed so measurements taken from stone models is indicative of the surface roughness. ${ }^{22}$ Each sample of soft lining materials was measured before and after in vitro accelerated weathering procedure.

\section{Adhesion Assay}

The 40 samples of each material were used for adhesion assay, and 20 of the samples were used after accelerated aging. Ten of the 20 samples of each material were coated with saliva. All samples were sterilized by ethylene oxide and aired for three days to remove residual ethylene oxide.

Fresh stimulated human whole saliva samples were collected from four healthy Candidates and were used the same day. The Candidates had not taken any medication during the preceding three months and had no active periodontal disease or active caries. Saliva secretion was stimulated using paraffin and collected on ice.
The collected saliva was centrifuged at $5000 \mathrm{Xg}$ for 15 minutes and the supernatant fluid was used. $^{23}$

The samples were immersed in the clarified saliva and incubated for one hour at $37^{\circ} \mathrm{C}$ then washed in distilled water for 30 seconds to remove unbound and loosely bound substances and allowed to air-dry for 24 hours.

\section{Preparation of Yeast Suspensions}

The C. albicans ATCC 90028 strain was used as a quality control. This was transferred onto Sabouraud dextrose agar Sigma-Aldrich, Inc., St. Louis, MO, USA) plates to re-grow the yeast colonies. The Candida culture was incubated in Sabouraud broth (Sigma-Aldrich, Inc., St. Louis, MO, USA) supplemented with $500 \mathrm{mmol} /$ It of sucrose. This medium was used because previous studies have shown increased candidal adherence to acrylic resin after culturing in Sabouraud's broth supplemented with sucrose. A loopful of Candida culture was incubated on Sabouraud broth for 24 hours at $37^{\circ} \mathrm{C}$ (Dedeoglu, Instanbul, Turkey) in a Thermolyne Maxi-mix III Type 65800 horizontal shaker (Barnstead International, Dubuque, IA, USA) in order to grow yeast cells in a stationary phase. The culture was centrifuged at $1700 \mathrm{xg}$ for ten minutes, and the resultant pellet was washed twice with phosphate buffered saline (PBS) solution $(0.15 \mathrm{~mol} / \mathrm{L}, \mathrm{pH}$ 7.2). A final yeast suspension of approximately $10^{7}$ yeast $/ \mathrm{ml}$ was prepared by adding PBS. The number of the yeast per $\mathrm{ml}$ was monitored in all the experiments by spectrophotometric counting using a Shimadzu UV-1201 (Shimadzu Precision Instruments, Torrance, CA, USA). ${ }^{11,24,25}$

Using strict aseptic techniques, the sample acrylic strips were placed in the tubes containing $4 \times 10^{7}$ yeasts in one $\mathrm{ml}$ of PBS. Tubes were placed in a shaker incubator for three hours at $37^{\circ} \mathrm{C}$ with gentle agitation. The strips were then 
washed in sterile distilled water, air-dried, and stained using a gram stain. After drying at room temperature, they were mounted on glass slides; the adherent yeasts were quantified using $X 40$ magnification under a light microscope. Ten fields were randomly counted on each strip, and all experiments were repeated on three separate occasions with duplicate determinations on each occasion (Table 3).

\section{Statistical Analysis}

Table 3. Adhesion scores.

\begin{tabular}{|l|l|}
\hline \multicolumn{1}{|c|}{ Adhesion Score } & \multicolumn{1}{c|}{ Cell Number } \\
\hline+ & $1-25$ \\
\hline++ & $25-50$ \\
\hline+++ & $50-75$ \\
\hline++++ & $75-100$ \\
\hline
\end{tabular}

One-way analysis of variance (ANOVA) was used to examine the differences in soft lining materials' surface roughness. Data collected were analyzed for homogeneity of variances using Levene's test. The results were considered significant at the 0.05 level only. All adhesion assay data obtained here were analyzed by Cramer's V.

\section{Results}

\section{Surface Roughness}

The results are presented as surface roughness values of average surface roughness measurements, and the results for surface roughness of soft lining materials according to the accelerated aging process are shown in Table 4.

As shown in Figure 1, aging essentially promoted the surface roughness of the materials. The aging surface roughness of Visco Gel was significantly higher than Ufi Gel P and Molloplast B.

There was a significant difference between variances (Levene's test $=48.333$ and $p<0.001$ ). Data collected from three soft lining material samples were analyzed first for homogeneity of variances using Levene's test followed by ANOVA. Homogeneity of variances was rejected because of the Visco Gel. Therefore, ANOVA was performed to compare Ufi Gel P and Molloplast B.

Molloplast B and Ufi Gel P were compared separately (Figure 2), and Molloplast B produced the smoothest surface after accelerated aging process $(F=11.705$ ve $p=0.003)$.

\section{Adherence of $C$. albicans}

Uncoated samples: The adherence of $C$. albicans between non-aged and uncoated materials was not significant (Cramers $\mathrm{V}=0.222$, $\mathrm{P}=0.56$ ). In the case of aged and uncoated samples the adherence of $C$. albicans was greatest on Molloplast B (Cramers, $\mathrm{P}=0.007$ ) (Table 5).

Saliva coated samples: No significant correlation was observed between the adherence of $C$. albicans on non-aged and saliva-coated samples (Cramer's $V=0.111, p=0.830$ ). In the case of aged and saliva coated samples the adherence of $C$. albicans was greatest on Molloplast B (Cramer's V $=0.468, p=0.041$ ) (Table 6).

\section{Discussion}

The accelerated aging process has been used to examine color change over time as well as changes in physical and mechanical properties of various materials, but little attention has been paid to the colonization of Candida when they aged. $^{19,20,26,27,28,29,30,31}$

In this study a simple in vitro model was used to compare the surface roughness and the adherence of $C$. albicans with three commercially available soft denture lining materials before and after an aging process. An aging device was used to subject soft lining material samples to both visible and UV light along with a distilled water spray to simulate aging. The manufacturer of the weathering instrument estimates 300 hours of aging are equivalent to one year of clinical service. ${ }^{31}$ In the present study the samples were stored in the accelerated aging chamber according to time limits recommended by the manufacturer for each lining material (Table 2). Dootz et al. ${ }^{20}$ and Kawona et al. ${ }^{30}$ stored the soft lining materials in an aging chamber for 900 hours, but this is not equivalent to their clinic usage time. 
Table 4. Mean surface roughness values and standard deviations for surface roughness, before (Ra1) and after (Ra2) accelerated aging and the difference values before and after accelerated aging (Ra1-Ra2).

\begin{tabular}{|l|c|c|c|}
\hline \multicolumn{1}{|c|}{ Materials } & Ra1 & Ra2 & Ra1-Ra2 \\
\cline { 2 - 4 } & Mean (SD) & Mean (SD) & Mean (SD) \\
\hline Visco Gel $(n=10)$ & $1.60(0.2055)$ & $16.67(3.2428)$ & $0.39(0.1197)$ \\
\hline Ufi Gel P $(n=10)$ & $1.47(0.2452)$ & $1.86(0.2836)$ & $0.24(0.0699)$ \\
\hline Molloplast $B(n=10)$ & $0.94(0.1578)$ & $1.18(0.2044)$ & \\
\hline
\end{tabular}

Ra: the arithmetical average of all departures of the profile through the mean sample length.

SD: standard deviation.

$\mathrm{n}$ : number of samples

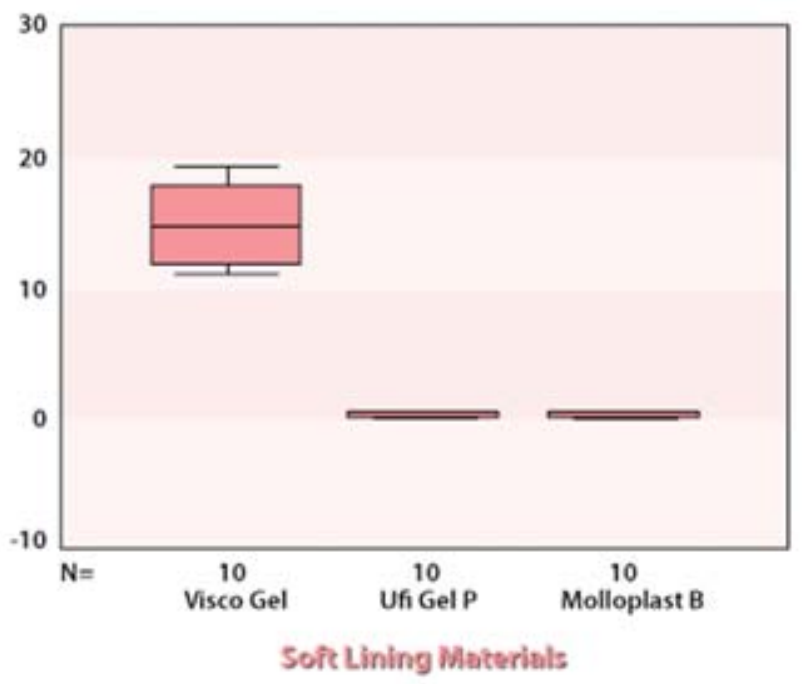

Figure 1. Differences on surface roughness values of soft lining materials according to the accelerated aging.

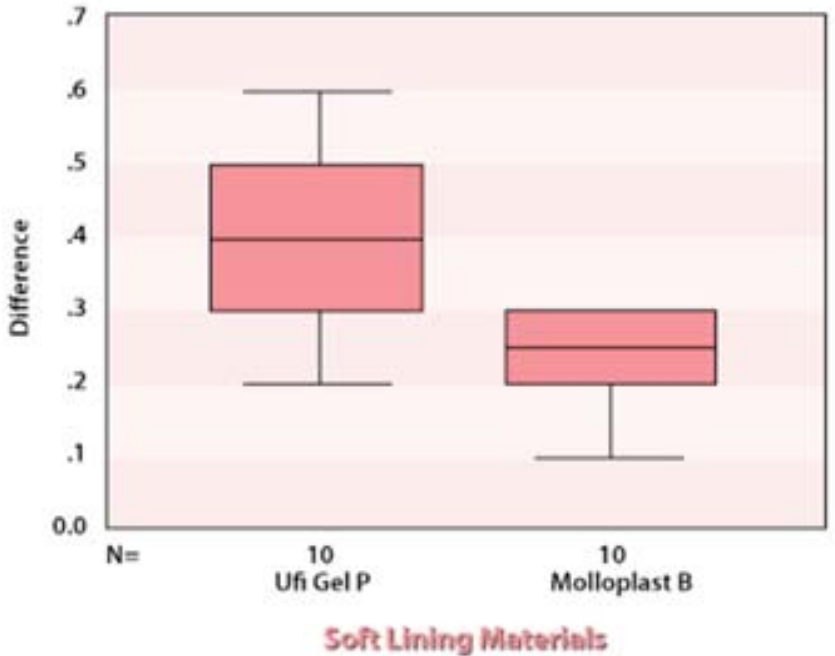

Figure 2. Differences on surface roughness values of Ufi Gel P vs Molloplast B according to the accelerated aging.

Table 5. Adhesion scores for uncoated soft lining materials before accelerated aging (UAS1) and after accelerated aging (UAS2).

\begin{tabular}{|l|c|c|c|c|c|c|}
\hline \multirow{2}{*}{ MATERIAL } & \multicolumn{3}{c|}{ UAS1 ${ }^{*}(n=30)$} & \multicolumn{4}{c|}{ UAS2** $(n=30)$} \\
\cline { 2 - 7 } & + & ++ & +++ & ++ & +++ \\
\hline Visco GeI $(n=20)$ & 7 & 2 & 1 & 0 & 8 & 2 \\
\hline Ufi Gel P $(n=20$ & 5 & 3 & 2 & 4 & 2 & 4 \\
\hline Molloplast B $(n=20)$ & 8 & 2 & 0 & 0 & 4 & 6 \\
\hline
\end{tabular}

${ }^{*}$ Cramer's V=0.222, $p=0.560$

${ }^{* *}$ Cramer's V $=0.483, p=0.007$

$\mathrm{n}$ : number of samples 
Table 6. Adhesion scores for saliva-coated soft lining materials before accelerated aging (CAS1) and after accelerated aging (CAS2).

\begin{tabular}{|l|c|c|c|c|c|c|}
\hline \multirow{2}{*}{ MATERIAL } & \multicolumn{3}{c|}{ CAS1* $(n=30)$} & \multicolumn{3}{c|}{ CAS2** $(n=30)$} \\
\cline { 2 - 8 } & + & ++ & +++ & ++ & +++ & 1 \\
\hline Visco Gel $(n=20)$ & 8 & 2 & 1 & 7 & 2 & 3 \\
\hline Ufi GeI P $(n=20$ & 7 & 3 & 2 & 3 & 2 & 5 \\
\hline Molloplast B $(n=20)$ & 8 & 2 & 3 & 0 & 2 & 5 \\
\hline
\end{tabular}

${ }^{*}$ Cramer's $\mathrm{V}=0.111, \mathrm{p}=0.830$

${ }^{* *}$ Cramer's V=0.468, $p=0.041$

n: number of samples

The surface roughness of a material used for a removable prosthesis is of importance since it affects, directly or indirectly, retention, staining resistance, plaque accumulation, as well as oral tissue health and patient comfort. ${ }^{11,32,33,34}$

In the present study we examined the surface roughness of soft lining materials before and after an aging process. After aging, all soft lining materials became rougher. The roughest was Visco Gel, and the least rough was Molloplast B before and after the aging process. The surface roughness value for Molloplast B and Visco Gel was found to be lower than reported by Zissis et al ${ }^{34}$ who found a surface roughness value for Molloplast B of $3.5 \mu \mathrm{m}$. and by Loney et al. ${ }^{35}$ who reported a surface roughness value for Visco Gel of $3.7 \mu \mathrm{m}$. This may be because of the different surface textures of the specimens caused by processing against different materials.

The findings in this study for Ufi Gel P samples showed surface roughness values are similar to those reported by Jin et al. ${ }^{9}$ This may be because the same indirect technique was used for measurement.

There were several papers suggesting the relationship between surface roughness and fungal adherence to denture materials. ${ }^{4,10,32}$ The surface roughness and adhesion of soft lining materials was analyzed using an aging process. In reviewing the pertinent literature no other studies using exactly the same aging process were found, so it is presumed only indirect comparisons are possible.
In this study a number of yeast cells were examined on the samples of each material before and after the in vitro accelerated aging process and analyzed the effect of saliva on the adherence of $C$. albicans. Some investigators point out the pellicle of salivary proteins may provide receptor sites for specific adherence of microorganisms. ${ }^{36}$ Some investigators have reported a coating of saliva reduced the adherence of $C$. albicans to soft lining materials ${ }^{4,11,37}$, while some showed the coating actually increased the adherence. ${ }^{38}$ The others have shown no effect of saliva on $C$. albicans adherence. ${ }^{13,39}$

According to the results of this study, adhesion of $C$. albicans to saliva coated and uncoated soft lining materials were not significant. However, aged Molloplast B samples had a higher candidal adherence than did Ufi Gel P and Visco Gel. The

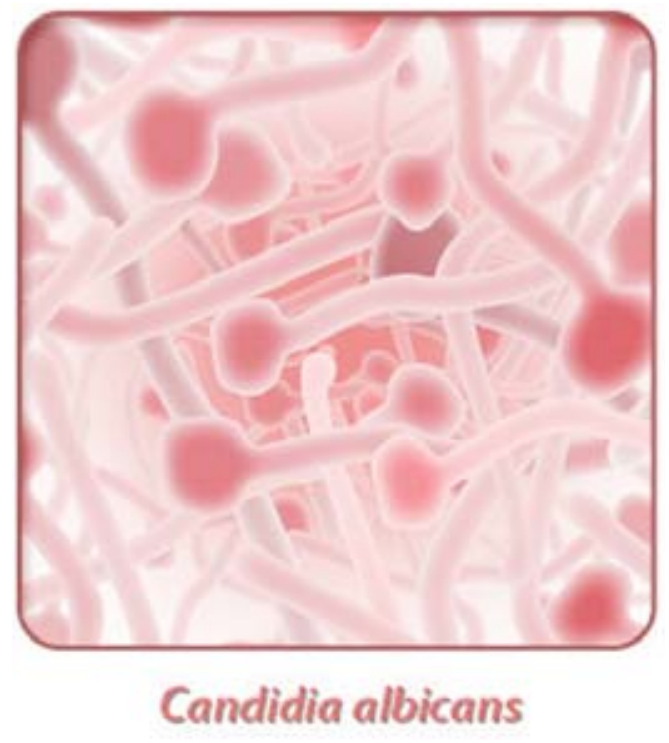


difference between saliva coated and non-aged soft lining materials was not significant, however, aged Molloplast B samples had higher candidal adherence than others.

Bulad et al. ${ }^{5}$ reported no difference in the adhesion of $C$. albicans between different soft lining materials processed against glass slides, and more adhesion was observed on Molloplast $B$ when processed against dental stone. No significant difference in the adhesion of $C$. albicans between non-aged soft lining materials was observed in the present study. The aging process essentially promoted the fungal adhesion on the uncoated and coated specimens with the greatest occuring on Molloplast B.

Surface roughness is a significant factor in the attachment and adhesion of microorganisms on surfaces with an increase in roughness causing increased retention of cells. ${ }^{4,10}$ In the present study the aging process increased the surface roughness of the soft lining materials, and $C$. albicans adhesion was increased on aged Molloplast B. The results of our study may be explained by the effect reported previously.

Saliva coating had no affect on the adherence of $C$. albicans to the non-aged specimens, but after the in vitro accelerated aging process fungal adherence to Visco Gel and Molloplast $B$ increased. This could be partly attributed to the reduction in the antifungal effect of soft lining materials by pellicle coatings. Nikawa et al. ${ }^{13,24}$, in their investigations on fungal adherence to soft lining materials with or without a salivary pellicle, showed there was no difference in fungal adherence to saliva coated soft lining materials.

The aging process essentially promoted the fungal colonization particularly on the coated specimens with the greatest being on Molloplast B. Since aging essentially promoted the fungal colonization, this can probably be attributed to the significant reduction in antifungal effects of the soft lining materials during the aging process.

\section{Conclusion}

This study has shown, for a given soft lining material, aging leads to increased surface roughness and the adhesion of $C$. albicans. The presence of a salivary pellicle derived from stimulated human whole saliva had no effect on the adhesion of non-aged soft lining materials, but after an accelerated aging process the adhesion of $C$. albicans increased. In many instances this increase was considerable since the aging process promoted the surface roughness of the soft lining materials.

It is important to use soft denture lining materials with smooth surfaces for this will lead to a reduction in the adherence of $C$. albicans, an opportunistic pathogen commonly associated with denture wearing. Awareness of the susceptibility of these materials is an important factor in their selection and use. 


\section{References}

1. Budtz-Jörgensen E. Etiology, pathogenesis, therapy, and prophylaxis of oral yeast infections: Acta Odontol Scand 1990;48:61-69.

2. Zegarelli DJ. Fungal infections of the oral cavity: Otolaryngol. Clin. North America 1993;26: 1069-1089.

3. Price C, Waters MGJ, Williams DW, Lewis MAO, Stickler D. Surface modification of an experimental silicone rubber aimed at reducing initial candidal adhesion. J Biomed Mater Res 2002;63:122-128.

4. Radford DR, Sweet SP, Challacombe SJ, Walter JD. Adherence of C. albicans to denture-base materials with different surface finishes. J Dent 1998;26:577-583.

5. Bulad K, Taylor RL, Verran J, McCord JF. Colonization and penetration of denture soft lining materials by C. albicans. Dent Mat 2004;20:167-175.

6. Mack PJ. Denture soft lining materials: clinical indications. Aust Dent 1989;34(5):454-458.

7. Nikawa $\mathrm{H}$, Hamada T. Binding of salivary or serum proteins to $C$. albicans in vitro. Archs Oral Biol 1990;35:571-573.

8. Garcia R, Leon BLT, Oliveira VMB, Del Bel Cury AA. Effect of a denture cleansers on weight, surface roughness, and tensile bond strength of two resilient denture liners. J Prosthet Dent 2003;89:489-494.

9. Jin $\mathrm{C}$, Nikawa $\mathrm{H}$, Makihira S, Hamada T, Furukawa M, Murata $\mathrm{H}$. Changes in surface roughness and color stability of soft lining materials caused by denture cleansers. J Oral Rehabil 2003;30: 125-130.

10. Verran J, Maryan CJ. Retention of $C$. albicans on acrylic resin and silicone of different surface topography. J Prosthet Dent 1997;77:535-539.

11. Waters MGJ, Williams DW, RG Jagger, MAO Lewis. Adherence of $C$. albicans to experimental denture soft lining materials. J Prosthet Dent 1997;777:306-312.

12. Okita N, Orstavik D, Orstavik J, Ostby K. In vivo and in vitro studies on soft denture materials: Microbial adhesion and tests for antibacterial activity. Dent Mater 1991;7:155-160.

13. Nikawa $\mathrm{H}$, Iwanaga $\mathrm{H}$, Kameda $\mathrm{M}$, Hamada $\mathrm{T}$. In vitro evaluation of $C$. albicans adherence to soft denture-lining materials. J Prosthet Dent 1992;68:804-808.

14. Nikawa $\mathrm{H}$, Jin $\mathrm{C}$, Hamada $\mathrm{T}$, Murata $\mathrm{H}$. Interactions between thermal cycled resilient denture lining materials, salivary and serum pellicles and $C$. albicans in vitro: Part I. Effects on fungal growth. J Oral Rehabil 2000;27:41-51.

15. Nikawa $H$, Jin $C$, Hamada $T$, Makihira S, Kumagai $H$, Murata $H$. Interactions between thermal cycled resilient denture lining materials, salivary and serum pellicles and $C$. albicans in vitro: Part II. Effects on fungal colonization. J Oral Rehabil 2000;27:124-130.

16. Radford DR, Watson TF, Walter JD, Challacombe SJ. The effects of surface machining on heat cured acrylic resin and two soft denture base materials: a scanning electron microscope and confocal microscope evaluation. J Prosthet Dent 1997;77:200-208.

17. Nikawa H, Jin C, Makihira S,Egusa H, Hamada T, Kumagai H. Biofilm formation of Candidia albicans on the surfaces of deteriorated soft denture lining materials caused by denture cleansers in vitro. J Oral Rehabil 2003;30:243-250.

18. Nikawa H, Hamada T, Takaharu Y. Denture Plaque-past and recent concerns. J Dent 1998;26: 299-304.

19. Fruits TJ, Duncanson MG, Miranda FJ. In vitro weathering of selected direct esthetic restorative materials. Quintessence Int 1997;28:409-414.

20. Dootz ER, Koran A, Craig RG. Physical property comparison of 11 soft denture lining materials as a function of accelerated aging. J Prosthet Dent 1993;69:114-119.

21. Yamuchi M, Yamamoto K, Wakabayashi M, Kawano J. In vitro adherence of microorganisms to denture base resin with different surface texture. Dent Mater J 1990;9:19-24.

22. Kent K, Ziegel RF. Surface topography of silicone rubber prosthetic materials fabricated using conventional processing techniques. J Prosthet Dent 1982;48:698-702.

23. Steinberg D, Mor C, Dogan H, Zacks B, Rotstein I. Effect of salivary biofilm on the adherence of oral bacteria to bleached and non-bleached restorative material. Dent Mat 1999;15:14-20. 
24. Nikawa $\mathrm{H}$, Hamada $\mathrm{T}$, Yamamoto $\mathrm{T}$, Kumagai $\mathrm{H}$. Effects of salivary or serum pellicles on the $C$. albicans growth and biofilm formation on soft lining materials in vitro. J Oral Rehabil 1997;24: 594-604.

25. Gokdal I, Kalkancı A, Pacal G, Altug Z. Candida colonization on the surface of orthodontic brackets and the adhesion of these strains to buccal epithelial cells. Mikrobiyol Bult 2002;36:65-69.

26. Noie F, O'Keefe KL, Powers JM. Color stability of resin cements after accelerated aging. Int J Prosthodont 1995;8:51-55.

27. Shotwell JL, Razzoog ME, Koran A. Color stability of long-term soft denture liners. J Prosthet Dent 1992;68:836-838.

28. Hekimoglu $\mathrm{C}$, Anil $\mathrm{N}$. The effect of accelerated ageing on the mechanical properties of soft denture lining materials. J Oral Rehabil 1999;26:745-748.

29. Anil N, Hekimoglu C, Buyukbas N, Ercan MT. Microleakage study of various soft denture liners by autoradiography: Effect of accelerated aging. J Prosthet Dent 2000;84:394-399.

30. Kawano F, Koran A, Nuryanti A, Inoue S. Impact absorption of four processed soft denture liners as influenced as influenced by accelerated aging. Int J Prosthodont 1997;10:55-60.

31. Anil N, Hekimoglu C, Sahin S. Color stability of heat autopolymerized soft denture liners. J Prosthet Dent 1999;81:481-484.

32. Quirynen M, Bollen CML. The influence of surface roughness and surface-free energy on supraand subgingival plaque formation in man. J Clin Periodontol 1995;22:1-14.

33. Wright PS, Young KA, Parker S, Kalchandra S. Evaluating the effect of soft lining materials on the growth of yeast. J Prosthet Dent 1998;79:404-409.

34. Zissiz AJ, Polyzoıs GL, Yannıkakıs SA, Harrison A. Roughness of Denture Materials: A Comparative Study. Int J Prosthodont 2000;13:136-140.

35. Loney RW, Moulding MB. The effect of finishing and polishing on surface roughness of tissue conditioners. Int J Prosthodont 2000;13:209-213.

36. Jones GW, Isaacson RE. Proteinaceous bacterial adhesions and receptors. CRC Crit Rev Microbiol 1983;10:229-260.

37. McCourtie J, MacFarlane TW, Samaranayake LP. Effect of saliva and serum on the adherence of Candida species to chlorhexidine-treated denture acrylic. J Med Microbiol 1986;21:209-213.

38. Nikawa H, Hayashi S, Nikawa Y, Hamada T, Samaranayake LP. Interactions between denture lining material, protein pellicles and C. albicans. Archs Oral Biol 1993;38:631-634.

39. Wright PS. The effect of soft lining materials on the growth of C. albicans. J Dent 1980;8:144. 
About the Authors
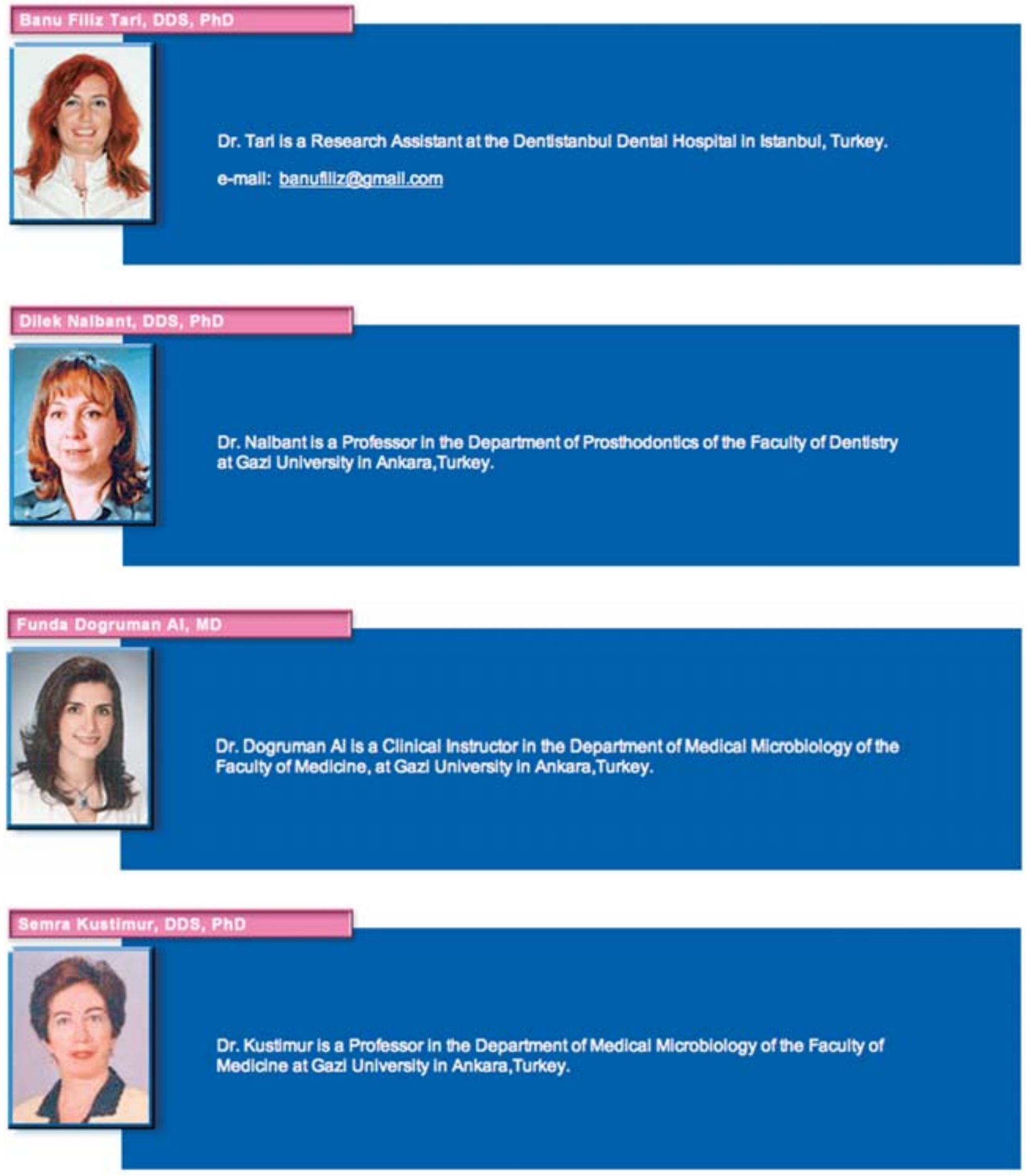